\title{
Matérista
}

ISSN 1517-7076

\section{Técnicas de carburação em fornos rotativos a óleo de xisto e gás natural para a produção de ferros fundidos}

\author{
M.F. Hupalo; F.G. Martins ${ }^{\mathrm{II}}$; D.S. Ramos ${ }^{\mathrm{II}}$; G. Warmling ${ }^{\mathrm{II}}$ \\ ${ }^{\mathrm{I}}$ Universidade Estadual de Ponta Grossa, Departamento de Engenharia de Materiais, Av. Gal. Carlos \\ Cavalcante, 4748, Bloco L, CEP.: 84030-000, Ponta Grossa, PR. \\ e-mail: mfhupalo@uepg.br \\ II Instituto Superior Tupy - Sociedade Educacional de Santa Catarina: Rua Albano Schmidt, 3333, Boa Vista, \\ CEP.: 89206-001, Joinville, SC. \\ e-mail: chico@sociesc.org.br ; daniele@sociesc.org.br ; guido@sociesc.org.br
}

\section{RESUMO}

A indústria metalúrgica tem buscado empregar processos de fusão mais eficientes. Os fornos rotativos a gás natural e óleo de xisto surgem como uma alternativa interessante para a produção de ligas ferrosas. Durante a fusão no forno rotativo acontece uma maior queima de elementos químicos, exigindo a utilização de técnicas de carburação adequadas. No presente trabalho foram avaliadas diferentes formas de adição de carburantes durante a fusão de ferros fundidos cinzentos e nodulares, utilizando fornos rotativos a óleo de xisto e gás natural. Dois tipos de carburantes, com diferentes granulometrias, foram adicionados em diferentes estágios do processo de fusão. Os resultados mostram que o rendimento de carburação é fortemente afetado pelo estado da carga metálica. O melhor rendimento foi obtido pelo carburante de coque de petróleo calcinado com granulometria de 1-3 mm, por meio da adição à carga no estado pastoso.

Palavras - chave: fornos rotativos, ferros fundidos, carburação.

\section{Carbonizing techniques in oil and gas-fired rotary furnaces for cast irons production}

\begin{abstract}
Metallurgic industry has sought for more efficient casting processes. Fuel oil and gas-fired rotary furnaces rise as an interesting alternative for cast irons production. It must be emphasized that during the fusion process in rotary furnaces, a higher burning of alloying elements occur, demanding the use of a suitable carbonizing technique in order to attend the chemical composition specifications. The present work aimed in the application and study of different carbonizing techniques during the production of gray and ductile cast irons using fuel oil and gas-fired rotary furnaces. Two carburant types with different particle sizes were added in different stages of fusion process. Results show that carbonizing efficiency is strongly affected by the state of the metallic charge. The best results were obtained by the calcined petroleum coke with a particle size of 1-3 mm, added to the pasty metal loading.
\end{abstract}

Keywords: rotary furnaces, cast irons, carbonizing.

\section{INTRODUÇÃO}

O Brasil já obteve destaque mundial por apresentar uma matriz energética global muito limpa, com altíssimo teor de uso de fontes renováveis [1]]. Entretanto, a indústria metalúrgica brasileira ainda oferece oportunidades para despoluir os seus processos, principalmente pela utilização do gás natural em fornos de processos metalúrgicos. Para tal, há necessidade do desenvolvimento de tecnologias, equipamentos, produtos e processos relacionados ao uso de gás natural no país, destacando-se: I) desenvolvimento de tecnologias e processos para auxiliar a agregação de valor a derivados; II) novos processos de conversão para líquidos; III) transporte, distribuição e armazenamento; IV) metrologia do gás natural; V) identificação de gargalos tecnológicos para o desenvolvimento do estado da arte; VI) tendências das tecnologias para energia; VII) mercado nacional de gás natural e VIII) aumento de eficiência na aplicação em equipamentos de uso final. 
O forno rotativo com queimador oxicombustível foi desenvolvido na Itália com o intuito de substituir o forno cubilô de geração mais antiga, na produção de ferro fundido cinzento, em função de sua grande poluição ambiental [2]. No Brasil, não há registros disponíveis relatando a introdução deste equipamento na indústria de fundição. A Sociedade Educacional de Santa Catarina - SOCIESC, nos idos de 1960, possuía um equipamento similar ao forno rotativo atualmente empregado nas fundições, usando como combustível o óleo diesel e ar. O forno era dotado de um sistema para aquecimento do ar usado na combustão. Na grande maioria das empresas que utilizam este tipo de forno, foi possível constatar que a introdução deste ocorreu por influência de engenheiros ou técnicos vindos da Europa.

Empresários da área de fundição relatam que a partir de 1985, no Brasil, percebeu-se uma maior divulgação deste equipamento por parte de empresas produtoras de gases comburentes, tendo em vista o consumo de oxigênio. Salienta-se que estas empresas não dominam a tecnologia de fabricação de ferros fundidos, muito menos o emprego de oxigênio na combustão para aquecimento de fornos. Por outro lado, a literatura nacional é carente de informações relativas ao desempenho do equipamento, efeito de variáveis de processamento na microestrutura, propriedades mecânicas dos materiais obtidos, níveis de emissão de poluentes, entre outros []ㅡ.

A utilização dos fornos rotativos vem aumentando muito nos últimos 10 anos, devido às características automáticas de operação, ao baixo custo de manutenção e à flexibilidade de produção; além da possibilidade de aplicação de diferentes tipos de combustíveis, tais como o gás natural (GN) e o óleo de xisto. O forno rotativo é especialmente apropriado a fundições pequenas ou de médio porte, cuja produção caracteriza-se pela presença de peças variadas e não-seriadas. De uma maneira geral, a qualidade das peças produzidas a partir deste tipo de forno é considerada boa. Vale destacar a possibilidade de obtenção de baixos teores de enxofre, o que constitui uma vantagem para a produção de ferros fundidos nodulares [4]].

A carburação de ferros fundidos é uma reação que depende basicamente do tempo, da temperatura e das concentrações relativas de carbono nas fases reagentes; enquanto sua eficiência está relacionada ao contato (molhabilidade) entre o produto carburante, que possui baixa densidade, e o metal, de alta densidade. A carburação consiste em adicionar carbono ao ferro. Quando o carbono entra em solução, admite-se que haja formação de uma camada limite na interface sólido-líquido, que é considerada estacionária e constituída por uma solução saturada de carbono líquido. Desta forma, as etapas, por meio das quais se processa a reação de dissolução de carbono, seriam:

I) reação de dissolução do carbono na interface sólido-líquido;

II) difusão do carbono através da camada limite; e

III) difusão do carbono para o interior do banho.

Considerando que o transporte de soluto para o interior do banho é, neste caso, mais rápido que a reação na interface e/ou que a difusão na camada limite, uma destas duas etapas poderia ser mais lenta, e, portanto, controladora do processo [ $[\underline{3}, \underline{4}$ ]. Podem existir diferenças sensíveis no rendimento da carburação, se o produto carburante for adicionado na carga fria, sobre o banho líquido ou pastoso, em separado ou juntamente com outros componentes da carga. Adições em cargas frias são consideradas mais vantajosas, devido ao fato de se ter um maior tempo para que as reações ocorram. Porém, nas adições em banhos líquidos os rendimentos são mais baixos e dependem de algumas variáveis, tais como densidade e granulometria do carburante e temperatura do banho [2, $\underline{3}]$.

Diante do exposto, o presente trabalho tem por objetivo principal avaliar diferentes formas de adição de carburantes, e os respectivos rendimentos de carburação, durante a fusão de ferros fundidos cinzentos (FC) e nodulares (FE), utilizando dados obtidos em dois fornos rotativos, um operando com óleo de xisto e outro com gás natural. Os experimentos foram realizados com o objetivo de estudar e aprimorar as técnicas de carburação, para possibilitar uma maior utilização do forno rotativo a gás natural, em substituição aos fornos a óleo. Vale ressaltar que os dois tipos de fornos possuem importantes diferenças do ponto de vista operacional, relacionadas ao tipo de combustível empregado e ao modelo de queimador.

\section{MATERIAIS E MÉTODOS}

\subsection{Fornos Rotativos}

Os testes de carburação foram realizados em dois tipos de fornos rotativos. O forno aquecido a óleo de xisto pertence a uma empresa de fundição de Joinville-SC, possui capacidade para $1600 \mathrm{~kg}$ e é utilizado principalmente para a produção de peças em ferro fundido nodular. O forno rotativo a gás natural, instalado na SOCIESC, com capacidade para $1500 \mathrm{~kg}$, possui um sistema de exaustão de gases e opera em escala experimental.

Os dois fornos utilizados possuem geometrias e dimensões muito semelhantes. O volume de trabalho consiste de uma seção cilíndrica com aproximadamente $1136 \mathrm{~mm}$ de diâmetro e $2604 \mathrm{~mm}$ de comprimento. O corpo cilíndrico do forno possui duas pistas de rolamento (vide Figura 1a) que permitem 
realizar o movimento de rotação, proporcionando melhor homogeneização da carga e recuperação do calor do refratário superior exposto à chama. Os fornos rotativos caracterizam-se por apresentar baixa convecção e elevada irradiação do refratário, maximizando a transferência de calor entre a parede do forno e a carga que está sendo fundida, encurtando o tempo necessário para o processo de pré-aquecimento. O movimento de rotação do forno é feito com auxílio de um motor elétrico acoplado a um redutor de velocidade (vide Figura 1b). O vazamento do metal é feito por dois orifícios (tapholes) diametralmente opostos, localizados a meia altura e no centro do comprimento da seção cilíndrica. Quando a carga está sendo processada, estes orifícios são fechados com massa refratária, retirada momentos antes do vazamento, feito pelo basculamento do forno.

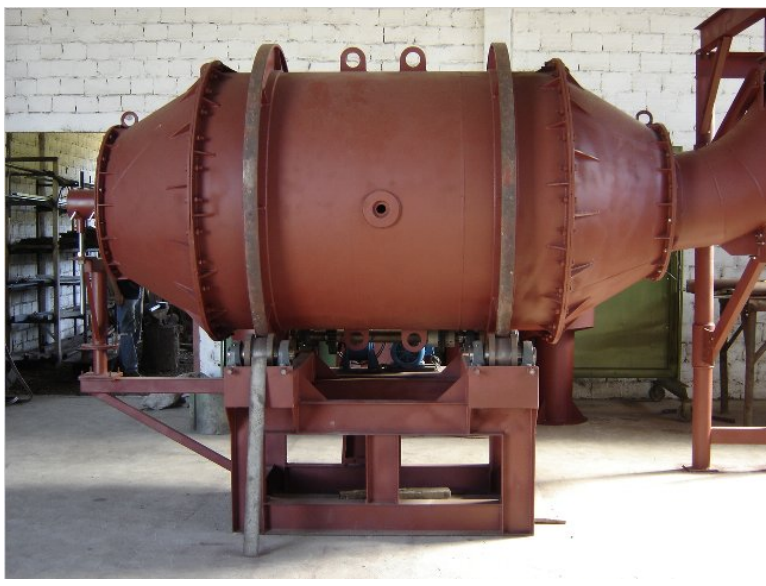

(a)

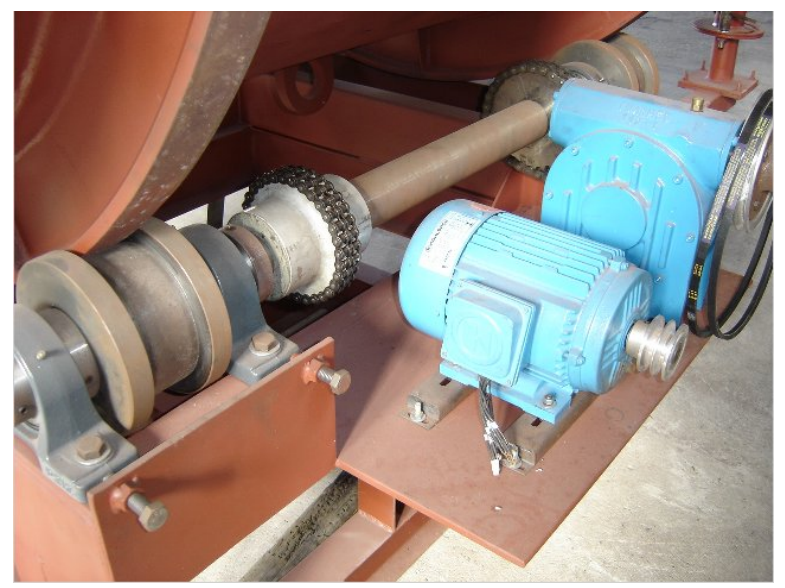

(b)

Figura 1: Detalhes construtivos do forno rotativo a gás natural: a) corpo cilíndrico com canal de vazamento e pistas de rolamento; b) sistema de acionamento composto por motor elétrico e redutor de velocidade.

\subsection{Fusões Experimentais}

Durante as fusões experimentais o forno rotativo a óleo de xisto consumiu 0,09 $\mathrm{m}^{3} / \mathrm{t}$ de óleo, 280 $\mathrm{m}^{3} / \mathrm{h}$ de oxigênio e a mesma vazão de ar comprimido para fundir $1600 \mathrm{~kg}$ de carga. O forno rotativo a gás natural, mostrado na Figura 1, consumiu em média $152 \mathrm{~m}^{3} / \mathrm{t}$ de óleo e $304 \mathrm{~m}^{3} / \mathrm{h}$ de oxigênio para fundir 1500 kg de carga. As misturas de combustíveis empregadas nos maçaricos, durante as fusões, foi desenvolvida dentro da empresa parceira e na SOCIESC com base em resultados práticos, visando, principalmente, a redução no tempo de fusão, com conseqüências diretas sobre a queima de elementos químicos da carga metálica, rendimento nos produtos adicionados e queima de componentes da carga metálica. As composições químicas dos materiais da carga dos fornos são mostradas nas Tabelas 1 e 2.

Tabela 1: Composição química analisada, em termos dos principais elementos de liga, dos materiais metálicos empregados na carga do forno a óleo de xisto (\% em peso).

\begin{tabular}{c|c|c|c|c|c}
\hline Elemento & Gusa FE & Gusa FC & Retorno FE & Retorno FC & Sucata FE \\
\hline C & 4,19 & 3,72 & 3,60 & 3,40 & 3,70 \\
Si & 0,65 & 2,50 & 2,40 & 2,20 & 2,40 \\
Mn & 0,20 & 0,70 & 0,25 & 0,45 & 0,20 \\
P & 0,09 & 0,086 & 0,06 & 0,07 & 0,04 \\
S & 0,013 & 0,009 & 0,01 & 0,08 & 0,01 \\
\hline
\end{tabular}

As fusões experimentais sempre foram iniciadas com a produção de ferro fundido cinzento, com o forno frio, visto que este metal necessita de menores temperaturas. As fusões de ferro fundido nodular foram realizadas após as fusões de ferro fundido cinzento e, portanto, com o forno já aquecido, em virtude do ferro fundido nodular necessitar de maiores temperaturas para apresentar boa fundibilidade. As temperaturas de vazamento do metal do forno para a panela de transferência foram da ordem de $1450^{\circ} \mathrm{C}$ para o ferro fundido cinzento e de $1560^{\circ} \mathrm{C}$ para o ferro fundido nodular. As cargas do forno, para a realização das fusões de ferros fundidos cinzentos e nodulares, foram constituídas de ferro gusa para ferro fundido cinzento (Gusa FC), ferro 
gusa para nodular (Gusa FE), retorno de ferro fundido cinzento (retorno FC), retorno de ferro fundido nodular (retorno FE) e sucata de ferro fundido nodular (sucata FE).

Tabela 2: Composição química analisada, em termos dos principais elementos de liga, dos materiais metálicos empregados na carga do forno a gás natural (\% em peso).

\begin{tabular}{c|c|c|c|c|c}
\hline Elemento & Gusa FE & Gusa FC & Retorno FE & Retorno FC & Sucata FE \\
\hline $\mathrm{C}$ & 4,12 & 3,78 & 3,55 & 3,44 & 3,75 \\
\hline $\mathrm{Si}$ & 1,10 & 2,05 & 2,42 & 2,18 & 2,38 \\
\hline $\mathrm{Mn}$ & 0,25 & 0,70 & 0,15 & 0,43 & 0,20 \\
\hline $\mathrm{P}$ & 0,09 & 0,086 & 0,08 & 0,08 & 0,04 \\
\hline $\mathrm{S}$ & 0,010 & 0,009 & 0,03 & 0,08 & 0,02 \\
\hline
\end{tabular}

Os valores aproximados de queima de elementos químicos da carga durante a fusão, considerados no cálculo de carga para efeito de correção de composição química na produção dos ferros fundidos cinzentos e nodulares, são apresentados na Tabela 3. Estes valores foram obtidos durante a realização de fusões prospectivas utilizando os mesmos fornos rotativos descritos no presente estudo. As composições químicas para os materiais estudados são apresentadas na Tabela 4. Os valores foram definidos tendo em vista as classes de materiais a serem produzidos para a aplicação nas peças fundidas. Em ferro fundido cinzento objetivou-se produzir a classe FC 200, enquanto que em ferro fundido nodular buscou-se a classe FE 60003.

Tabela 3: Valores aproximados de queima de carbono, silício e manganês, durante a fusão em fornos rotativos a óleo de xisto e gás natural (\% em peso).

\begin{tabular}{c|c|c|c|c}
\hline \multirow{2}{*}{ Elemento } & \multicolumn{2}{|c|}{ Forno rotativo a óleo } & \multicolumn{2}{c}{ Forno rotativo a gás natural } \\
\cline { 2 - 5 } & FC (\%) & FE (\%) & FC (\%) & FE (\%) \\
\hline C & 13 & 15 & 14 & 16 \\
\hline Si & 11 & 15 & 16 & 18 \\
\hline $\mathrm{Mn}$ & 30 & 35 & 29 & 37 \\
\hline
\end{tabular}

Tabela 4: Composições químicas especificadas para os ferros fundidos cinzentos e nodulares (\% em peso).

\begin{tabular}{c|c|c}
\hline \multirow{2}{*}{ Elemento } & \multicolumn{2}{|c}{ Composição (\% em peso) } \\
\cline { 2 - 3 } & Ferro fundido cinzento & Ferro fundido nodular \\
\hline $\mathrm{C}$ & 3,45 & 3,80 \\
\hline $\mathrm{Si}$ & 2,20 & 2,40 \\
\hline $\mathrm{Mn}$ & $<0,60$ & $<0,20$ \\
\hline $\mathrm{P}$ & $<0,10$ & $<0,07$ \\
\hline $\mathrm{S}$ & $<0,10$ & $<0,015$ \\
\hline $\mathrm{Sn}$ & - & 0,04 \\
\hline $\mathrm{Mg}$ & - & $0,03-0,06$ \\
\hline $\mathrm{Fe}$ & balanço & balanço \\
\hline
\end{tabular}

\subsection{Técnicas de Carburação e Cálculo de Rendimento}

Nos testes de carburação foram empregados dois tipos de carburantes muito utilizados nas fundições, sendo eles: i) coque de petróleo calcinado com duas faixas de granulometria, de 1-3 mm e de 3-6 
mm; e ii) grafita granulada com granulometria de 1-1,7 mm. A composição química destes carburantes é apresentada na Tabela 5. O carburante composto por coque de petróleo calcinado é o mais empregado nas fundições, tendo em vista seu menor custo em relação à grafita granulada; no entanto, este apresenta em sua composição maior presença de nitrogênio que pode contribuir, em certas condições, para o surgimento de defeitos de fundição do tipo "pinholes" (porosidades devidas a gases) nas peças fundidas. As seguintes técnicas de adição de carburantes foram empregadas durante as fusões experimentais: a) sobre o metal líquido, após a retirada da escória; b) junto com a carga sólida aquecida; e c) com o metal no estado pastoso.

A porcentagem de carburante adicionada foi de aproximadamente 1,0\% para ferro o fundido cinzento e de 1,6\% para o ferro fundido nodular. A técnica de carburação normalmente adotada pelas empresas que utilizam fornos rotativos consiste na adição do carburante sobre o banho de metal líquido, após a retirada de escória. A primeira técnica de adição dos carburantes, sobre o metal líquido, foi realizada imediatamente após a remoção da escória, com o queimador do forno desligado. O carburante foi mantido sobre o metal por aproximadamente 5 minutos, com o queimador do forno desligado, mantendo-se o forno girando, com o objetivo de homogeneizar a carga e permitir uma melhor incorporação de carbono à mesma.

Tabela 5: Composições químicas aproximadas do coque de petróleo calcinado e da grafita granulada.

\begin{tabular}{c|c|c}
\hline \multirow{2}{*}{ Componentes } & \multicolumn{2}{|c}{ Concentração (\%) } \\
\cline { 2 - 3 } & Coque de petróleo calcinado & Grafita granulada \\
\hline Carbono & 98,4 & 94,3 \\
\hline Cinzas & 0,75 & 5,40 \\
\hline Umidade & 0,30 & 0,18 \\
\hline Enxofre & 0,63 & 0,034 \\
\hline Matéria volátil & 0,45 & 0,98 \\
\hline Nitrogênio & 0,12 & 0,022 \\
\hline
\end{tabular}

No segundo método de carburação estudado, os carburantes foram adicionados à carga sólida, tão logo a mesma estivesse rubra. Neste caso o forno foi desligado, realizando-se a adição do carburante com o forno em rotação. Terminada a adição do carburante a chama do forno foi ligada imediatamente, evitando-se queda acentuada da temperatura. A terceira forma de adição do carburante consistiu na introdução deste no forno tão logo a carga atingisse o estado pastoso. A homogeneização da carga para incorporação do carburante também foi realizada com o queimador desligado.

Os rendimentos de carburação foram calculados com auxílio do seguinte procedimento:

a) estimou-se a quantidade de carbono inicial da carga metálica do forno, por meio de cálculos estequiométricos, a partir das composições químicas dos componentes das cargas metálicas, que foram apresentadas nas Tabelas 1 e 2. Com base nestes dados e na quantidade relativa dos componentes da carga, o teor de carbono inicial aproximado foi calculado para cada uma das fusões realizadas;

b) foram determinados os teores de carbono dos carburantes utilizados. Estes valores foram apresentados na Tabela 5. A partir destas composições pôde-se estimar a quantidade de carbono incorporada à carga metálica durante a etapa de adição dos carburantes; e

c) os resultados das análises químicas das amostras fundidas forneceram os teores de carbono finais das ligas elaboradas. O rendimento da técnica de carburação utilizada foi estimado com base na diferença entre o teor de carbono inicial da carga e o teor de carbono final das ligas fundidas.

\subsection{Tratamentos de Inoculação e Nodularização e Vazamento}

A inoculação do ferro fundido cinzento foi realizada pela adição de $0,3 \%$ (em peso) de inoculante Fe-Si (75\%), na passagem do metal do forno para a panela de transferência. A inoculação do ferro fundido nodular foi realizada na passagem do metal da panela de nodularização para a panela de vazamento, empregando-se 0,6\% (em peso) de inoculante Fe-Si (75\%). O tratamento de nodularização foi realizado pelo método "sandwich", em panela com capacidade para $280 \mathrm{~kg}$ de metal, empregando-se 2,0\% (em peso) de liga Fe-Si-Mg. O vazamento do metal líquido para os moldes foi realizado com o auxílio de panelas com capacidade para $35 \mathrm{~kg}$ de metal líquido. Imagens do procedimento de vazamento, nos fornos a óleo de xisto e a gás natural são apresentadas, nas Figuras 2(a) e 2(b), respectivamente. Amostras para análises químicas foram obtidas a partir de blocos Y de $25 \mathrm{~mm}$ de espessura. Os moldes dos blocos Y foram confeccionados em areia, pelo processo de cura a frio. 


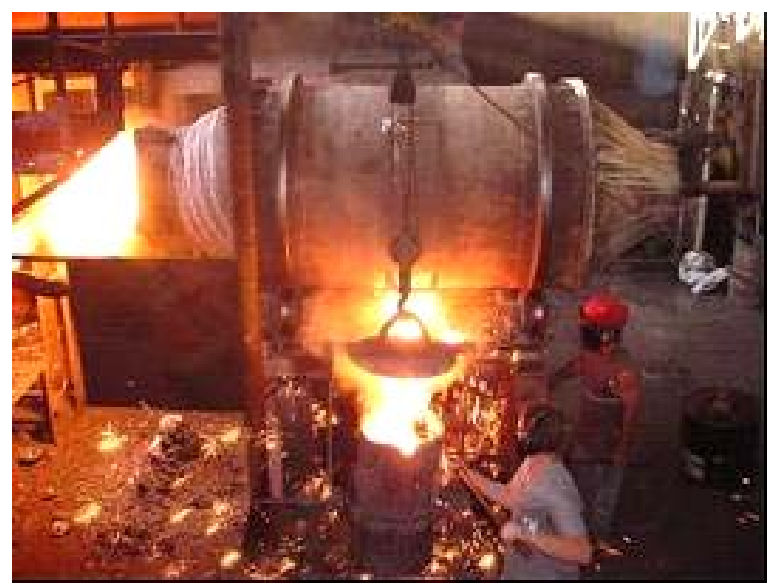

(a)

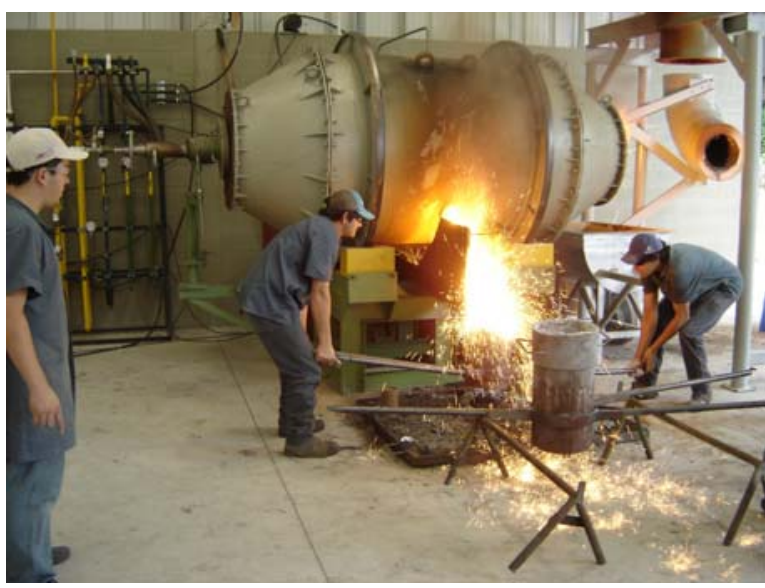

(b)

Figura 2: Operações de vazamento nos fornos rotativos a óleo de xisto (a) e gás natural (b).

\section{RESULTADOS}

\subsection{Adição de Coque de Petróleo Calcinado (1-3 mm) em Diferentes Estágios da Carga}

Na Tabela 6 são apresentados os valores de rendimento do carburante de coque de petróleo calcinado, com granulometria de 1 a $3 \mathrm{~mm}$, adicionado sobre o metal líquido durante a produção de ferros cinzentos e nodulares em fornos rotativos a óleo e gás natural.

Uma primeira análise dos dados da Tabela 6 permitiria supor que o rendimento do carburante de coque de petróleo é maior no ferro fundido cinzento que no ferro fundido nodular. Entretanto, este resultado pode estar associado à composição da carga utilizada para a fusão do ferro cinzento, que emprega menor porcentagem de ferro gusa. Outro fator relevante é a composição química final desejada para o primeiro, que apresenta menor teor de carbono e, portanto, exige menores taxas de incorporação de carbono ao banho.

Bernard et al. [2] citam que quanto mais fina a carga mais rápida a fusão e, conseqüentemente, menor a perda de elementos químicos por oxidação. Por outro lado, como o teor de carbono desejado em ferro fundido nodular é sempre maior que do ferro fundido cinzento (vide Tabela 4), há uma maior dificuldade de dissolução do carburante no metal líquido, visto que a composição da carga já possui teor de carbono mais elevado, por meio do emprego de elevada porcentagem de ferro gusa na carga inicial do forno.

Outro fator que merece destaque é o fato do acionamento do queimador do forno a gás natural promover forte corrente de gases quentes, que arrasta praticamente todo o carburante não dissolvido que ainda se encontra por cima do metal líquido, projetando o mesmo para fora do forno. Zhou et al. [్] relatam que um queimador a oxicombustível típico, em regime de operação durante a fusão, produz fluxos de gases com velocidades entre 40 e $60 \mathrm{~m} / \mathrm{s}$. Outros autores $[\underline{2}, \underline{4}, \underline{6}]$ afirmam que a turbulência e o arraste mecânico produzido por estes campos de velocidades são os principais inconvenientes operacionais da utilização de fornos rotativos.

Tabela 6: Rendimentos da adição do carburante de coque de petróleo adicionado sobre o metal líquido.

\begin{tabular}{c|c|c|c|c}
\hline Material & \multicolumn{2}{|c|}{ Ferro fundido cinzento } & \multicolumn{2}{c}{ Ferro fundido nodular } \\
\hline Forno & Óleo de xisto & Gás natural & Óleo de xisto & Gás natural \\
\hline Rendimento (\%) & 30,1 & 31,4 & 24,2 & 25,7 \\
\hline
\end{tabular}

Os rendimentos do carburante coque de petróleo calcinado, com granulometria de 1 a $3 \mathrm{~mm}$, quando adicionado à carga sólida aquecida, durante a produção de ferros cinzentos e nodulares, em fornos rotativos a óleo de xisto e gás natural, são apresentados na Tabela 7. Observa-se que o rendimento de carburação por adição à carga sólida é maior que o obtido pela adição ao metal líquido (Tabela 6), em especial na fusão de ferros fundidos nodulares, para os quais a técnica de carburação é mais crítica, em função dos maiores teores de carbono envolvidos, tanto na composição de carga como na composição química da liga.

Tabela 7: Rendimentos da adição do carburante de coque de petróleo adicionado à carga sólida aquecida. 


\begin{tabular}{c|c|c|c|c}
\hline Material & \multicolumn{2}{|c|}{ Ferro fundido cinzento } & \multicolumn{2}{c}{ Ferro fundido nodular } \\
\hline Forno & Óleo de xisto & Gás natural & Óleo de xisto & Gás natural \\
\hline Rendimento (\%) & 33,2 & 32,5 & 30,8 & 28,4 \\
\hline
\end{tabular}

O rendimento do carburante de coque de petróleo calcinado também foi determinado por meio da adição do mesmo à carga no estado pastoso. Os resultados obtidos para esta forma de adição são apresentados na Tabela 8. Constata-se que esta técnica de adição proporcionou os melhores resultados de rendimento, chegando a 55,7\% para as ligas de ferro cinzento produzidas em forno a óleo de xisto.

Tabela 8: Rendimentos da adição do carburante de coque de petróleo adicionado à carga no estado pastoso.

\begin{tabular}{c|c|c|c|c}
\hline Material & \multicolumn{2}{|c|}{ Ferro fundido cinzento } & \multicolumn{2}{c}{ Ferro fundido nodular } \\
\hline Forno & Óleo de xisto & Gás natural & Óleo de xisto & Gás natural \\
\hline Rendimento (\%) & 55,7 & 52,6 & 33,1 & 34,2 \\
\hline
\end{tabular}

Tabela 9: Rendimentos do carburante de coque de petróleo em função do estado da carga metálica.

\begin{tabular}{c|c|c|c|c|c|c}
\hline Material & \multicolumn{3}{|c|}{ Ferro fundido cinzento } & \multicolumn{3}{c}{ Ferro fundido nodular } \\
\hline Condição da carga & Sólida & Líquida & Pastosa & Sólida & Líquida & Pastosa \\
\hline Rendimento (\%) & 30,4 & 33,7 & 53,2 & 25,6 & 29,0 & 33,1 \\
\hline
\end{tabular}

Os experimentos realizados permitiram comparar os rendimentos das diferentes técnicas de carburação utilizadas. Com auxílio da Tabela 9 pode-se realizar uma análise comparativa dos rendimentos do carburante de coque de petróleo calcinado quando adicionado ao metal líquido, à carga sólida e à carga no estado pastoso. A adição do carburante à carga no estado pastoso apresentou o maior rendimento, tanto para a fusão de ferro fundido cinzento quanto para ferro fundido nodular. O rendimento superior da adição de carburante no estado pastoso está provavelmente associado à retenção deste pela carga, propiciando maior tempo de contato com o metal, minimizando, desta forma, sua projeção para fora do forno durante o processo de fusão. Apesar da diferença nos valores de rendimento entre as ligas de cinzento e nodular, ambas apresentaram a mesma tendência, ou seja, o aumento do rendimento de carburação da carga sólida, para a carga pastosa.

\subsection{Adição de Coque de Petróleo Calcinado, com Diferentes Granulometrias, à Carga Pastosa}

Os resultados apresentados no item anterior suscitaram a realização de experimentos complementares com carburante de coque de petróleo calcinado, com diferentes granulometrias. A técnica de carburação escolhida foi a de adição à carga metálica no estado pastoso. Os rendimentos de carburação com coque de petróleo calcinado, com granulometrias de 1-3 mm e 3-6 mm, durante a fusão de ferros fundidos cinzentos e nodulares, são apresentados na Tabela 10.

Os resultados da Tabela 10 mostram que o carburante de coque de petróleo calcinado com granulometria de 3 a $6 \mathrm{~mm}$ de diâmetro possui menor rendimento, tanto para a fusão de ferros fundidos cinzentos quanto de ferros fundidos nodulares. Estes resultados podem estar associados à menor área superficial de contato entre o carburante e a carga metálica, para o coque de petróleo de granulação mais grosseira, com conseqüente queda de rendimento do processo de incorporação de carbono ao banho.

Tabela 10: Rendimentos do carburante de coque de petróleo calcinado, com granulometrias de 1-3 e 3-6 mm, após adição à carga metálica no estado pastoso. Valores em \%.

\begin{tabular}{c|c|c|c|c}
\hline Material & \multicolumn{2}{|c|}{ Ferro fundido cinzento } & \multicolumn{2}{c}{ Ferro fundido nodular } \\
\hline Forno & Óleo de xisto & Gás natural & Óleo de xisto & Gás natural \\
\hline Granulometria de $1-3 \mathrm{~mm}$ & 55,6 & 50,3 & 33,7 & 33,4 \\
\hline Granulometria de 3-6 mm & 31,0 & 29,2 & 29,1 & 30,5 \\
\hline
\end{tabular}

\subsection{Adição de Coque de Petróleo Calcinado e Grafita Granulada à Carga Pastosa}

A etapa seguinte do trabalho consistiu na avaliação dos rendimentos de dois diferentes tipos de carburantes, o coque de petróleo calcinado com granulometria de 1-3 mm e a grafita granulada, com tamanho 
de partícula entre 1-1,7 mm. Ambos os carburantes foram adicionados à carga pastosa. Os resultados obtidos são apresentados na Tabela 11. Os resultados mostram que o carburante de grafita granulada apresentou menor rendimento que o de coque de petróleo calcinado. Este último mostrou-se mais adequado à incorporação de carbono ao banho, apesar de possuir maiores tamanhos de partícula em relação à grafita granulada. Vale mencionar que o maior rendimento do carburante de grafita granulada no ferro fundido cinzento pode estar associado à composição da carga metálica. Na produção de ferros fundidos nodulares utiliza-se maior porcentagem de ferro gusa, o que propicia maior teor de carbono na carga inicial, dificultando a incorporação de carbono ao banho líquido durante a etapa de carburação.

Tabela 11: Rendimentos dos carburantes de coque de petróleo calcinado e grafita granulada, após adição à carga metálica no estado pastoso. Valores em \%.

\begin{tabular}{c|c|c|c|c}
\hline Material & \multicolumn{2}{|c|}{ Ferro fundido cinzento } & \multicolumn{2}{c}{ Ferro fundido nodular } \\
\hline Forno & Óleo de xisto & Gás natural & Óleo de xisto & Gás natural \\
\hline Coque de petróleo $(1-3 \mathrm{~mm})$ & 55,0 & 50,0 & 33,0 & 33,0 \\
\hline Grafita granulada $(1-1,7 \mathrm{~mm})$ & 37,0 & 36,0 & 26,0 & 25,0 \\
\hline
\end{tabular}

\section{CONCLUSÕES}

As principais conclusões do presente trabalho são as seguintes:

1) O rendimento do carburante de coque de petróleo calcinado com granulometria de 1-3 mm, quando adicionado no forno sobre o metal líquido, é baixo, tanto em ferro fundido cinzento quanto em ferro fundido nodular. Atribuiu-se este resultado à dificuldade de agitação do banho e ao pequeno tempo de permanência do carburante sobre o metal líquido. O alto arraste mecânico gerado pelas características do queimador a oxi-combustível é responsável pela projeção de parte do carburante para fora do forno, antes de sua incorporação ao banho líquido.

2) A adição do coque de petróleo calcinado à carga sólida, ao invés da carga líquida, propiciou aumentos de rendimento médios da ordem de $10 \%$ para os ferros fundidos cinzentos, e de $16 \%$ para os ferros fundidos nodulares. Este resultado pode estar associado a um maior tempo de permanência do carburante em contato com o metal. O melhor rendimento do carburante de coque de petróleo calcinado com granulometria de 1 a $3 \mathrm{~mm}$ foi obtido quando este foi adicionado à carga no estado pastoso. Neste caso, grande parte da massa de carburante adicionada é envolvida pelo metal, evitando a expulsão do carburante do forno por arraste mecânico causado pelo posterior acionamento do queimador.

3) O aumento de granulometria do carburante de coque de petróleo calcinado de 1-3 para 3-6 mm, com adição à carga pastosa, resultou em sensível queda no rendimento de carburação. A adição de carburante de grafita granulada $(1-1,7 \mathrm{~mm})$ apresentou rendimento inferior ao do carburante de coque de petróleo calcinado com granulometria de 1-3 mm.

4) O maior rendimento de carburação do coque de petróleo calcinado, com granulometria de 1-3 $\mathrm{mm}$, adicionado à carga pastosa, pode contribuir para uma efetiva redução de consumo de carburante durante as operações de fusão, com conseqüentemente redução do custo de produção das peças fundidas.

\section{AGRADECIMENTOS}

Os autores agradecem à FINEP/MCT - Financiadora de Estudos e Projetos, à Petrobrás - Petróleo Brasileiro S.A. e à SCGÁS - Companhia de Gás de Santa Catarina, pelo apoio financeiro dado no âmbito do projeto “Aplicação de gás natural para a fusão de ligas ferrosas (FORNOROTAT)”. Agradecimentos também são devidos à Fundição Minatti Ltda., por possibilitar a realização dos testes com forno rotativo a óleo de xisto.

\section{BIBLIOGRAFIA}

[1] Balanço Energético Nacional 2009, EPE, MME, disponível em: https://ben.epe.gov.br/downloads/Relatorio_Final_BEN_2009.pdf, Acessado em 2009.

[2] BERNARD, J. C., FOULARD, J, DARLE, T, QUEVAL, B., "Melting and holding of iron in the rotary furnace with oxy-fuel burner”, Fonderie Fondeur d'Aujourd'Hui, n. 94, pp. 23-34, 1990.

[3] WARMLING, G. “Avaliação da carburação em forno rotativo”, Trabalho de conclusão de curso. UEPG/SOCIESC, Joinville, SC, Brasil, 2004. 
[4] TOSI, G.; PEDACI, A. "Produção de ferros fundidos em fornos tipo tambor rotativo”, Revista Fundição e Serviço, pp. 56-65, 1995.

[5] ZHOU, B., YANG, Y., REUTER, M.A., BOIN, U.M.J., "Modelling of aluminium scrap melting in a rotary furnace”, Minerals Engineering, v. 19, pp. 145-163, 2006.

[6] ZHANG, Y., BARR, P.V., MEADOWCROFT, T.R., "Continuous scrap melting in a short rotary furnace”, Minerals Engineering, v. 21, pp. 178-189, 2008. 